\title{
Synthesis and Structure-Activity Relationship of Dehydrodieugenol B Neolignans against Trypanosoma cruzi
}

\author{
Claire E. Sear, Pauline Pieper, Maiara Amaral, Maiara M. Romanelli, Thais A. Costa-Silva, \\ Marius M. Haugland, Joseph A. Tate, João H. G. Lago, Andre G. Tempone,* and Edward A. Anderson*
}

Cite This: ACS Infect. Dis. 2020, 6, 2872-2878

Read Online

Supporting Information

ABSTRACT: Trypanosoma cruzi is the etiologic agent of Chagas disease, which affects over seven million people, especially in developing countries. Undesirable side effects are frequently associated with current therapies, which are typically ineffective in the treatment of all stages of the disease. Here, we report the first synthesis of the neolignan dehydrodieugenol $\mathrm{B}$, a natural product recently shown to exhibit activity against T. cruzi. Using this strategy, a series of synthetic analogues were prepared to explore structure-activity relationships. The in vitro antiparasitic activities of these analogues revealed a wide tolerance of

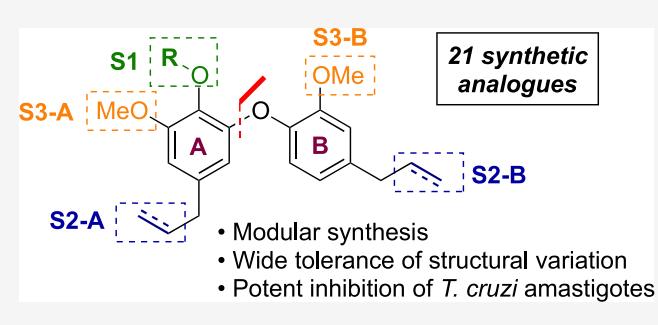
modifications and substituent deletions, with maintained or improved bioactivities against the amastigote forms of the parasite ( $50 \%$ inhibitory concentration $\left(\mathrm{IC}_{50}\right)$ of $\left.4-63 \mu \mathrm{M}\right)$ and no mammalian toxicity $\left(50 \%\right.$ cytotoxic concentration $\left(\mathrm{CC}_{50}\right)$ of $\left.>200 \mu \mathrm{M}\right)$. Five of these analogues meet the Drugs for Neglected Disease Initiative (DNDi) "hit criteria" for Chagas disease. This work has enabled the identification of key structural features of the natural product and sites where scaffold modification is tolerated.

KEYWORDS: Trypanosoma cruzi, Chagas disease, natural product, neolignan, SAR

C hagas disease, a neglected tropical disease caused by the kinetoplastid parasite Trypanosoma cruzi, affects 6-7 million people worldwide and causes $\sim 14000$ deaths per year. ${ }^{1,2}$ It is endemic in Latin American countries and is spreading further worldwide due to human and vector migration. ${ }^{3}$ The disease consists of a mostly asymptomatic acute stage, which is typified by the presence of parasites in the blood, and a chronic stage, where the level of parasite in the blood is low/undetectable due to their predominant location in the heart and digestive system. While the chronic phase can persist undetected for decades, ${ }^{4} 30-40 \%$ of patients suffer severe failure of vital organs (e.g., cardiomyopathy and gastrointestinal disease), leading to major disability or death. ${ }^{5}$ Current treatments (nifurtimox and benznidazole) cause severe side effects and are inefficient in the chronic stage of the disease, and parasite resistance is emerging. ${ }^{6}$ Despite efforts to develop new antiparasitic agents, ${ }^{7,8}$ the current pipeline for chemical entities against T. cruzi is limited, and as such, there is an ongoing need for new drug candidates., ${ }^{9,10}$

Natural products are a proven source of drugs, either in their natural form, as synthetic/semisynthetic derivatives, or as a basic pharmacophore. ${ }^{11}$ Parasitic diseases are no exception, ${ }^{12-15}$ with the frontline treatments for malaria (artemisinin) and visceral leishmaniasis (amphotericin B and paromomycin) themselves being natural products. ${ }^{16,17}$ As part of a program to identify new antitrypanosomal agents, we previously reported the isolation of dehydrodieugenol B (1, Figure 1) and methyl dehydrodieugenol B (2) from the plant Nectandra leucantha and their bioactivity against T. cruzi. ${ }^{18,19} \mathrm{~A}$

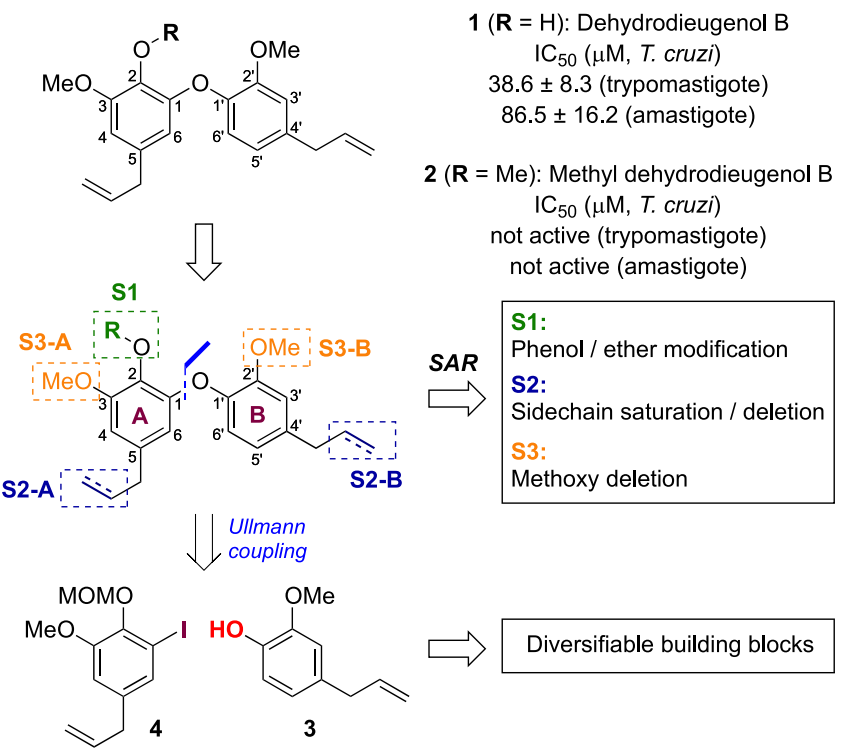

Figure 1. Structures of the dehydrodieugenol natural products and planned SAR/synthesis strategy.

Received: July 21, 2020

Published: October 13, 2020 
series of semisynthetic analogues was subsequently investigated, ${ }^{20}$ which were accessed by modification of the phenol and allyl side chains of dehydrodieugenol B. This suggested that at least one nonpolar side chain is required for activity, as the introduction of polar functionalities onto both (a necessary consequence of this semisynthesis approach) resulted in a notable reduction in bioactivity.

To establish a more detailed structure-activity relationship (SAR) for dehydrodieugenol $\mathrm{B}$, we targeted a concise and robust strategy that would enable facile modification of the natural product core, including selective substitution/deletion of key structural features. We were attracted to a coppercatalyzed biaryl ether formation as a key disconnection (Ullmann coupling, Figure 1), as this would segment the natural product into the readily available eugenol (3) and eugenol-derived iodide (4); analogues would be accessed by the variation of either partner. From an SAR perspective, three sets of modifications were targeted: (1) the phenol/OMe group at $\mathrm{C} 2$ on the A-ring (substituent S1, green); (2) the allyl side chains (substituents S2, blue); (3) the methoxy groups (substituents S3, orange). Here, we describe the development of this synthetic strategy to access natural products $\mathbf{1}$ and 2, its application to prepare 21 analogues (5-25), and the evaluation of their bioactivity against $T$. cruzi.

Copper-catalyzed Ullmann coupling represents an attractive method to access biaryl ethers. ${ }^{21-23}$ However, this particular $\mathrm{C}-\mathrm{O}$ bond formation is challenged by the need for an electron-rich halide and steric hindrance (ortho-substitution) on both coupling partners. The need for basic reaction conditions leads to an additional concern, which has been encountered in work toward related natural products, ${ }^{24}$ namely, isomerization of the allylic side chain to the more thermodynamically favored internal alkene.

The Ullmann coupling conditions described by Buck et al. were chosen as a starting point to study biaryl ether formation, ${ }^{25}$ as they were successfully employed using electron-rich halides and sterically hindered substrates. In order to optimize the conditions for our system, commercially available 2-iodoanisole (26) was first used as a coupling partner with eugenol (Table 1). Under the reported conditions, ${ }^{25}$ isomerization of the allylic side chain proved to be a significant problem (Entry 1), with desired product 27 being the minor component of the product mixture. The use of bromoanisole (Entry 2) exacerbated this problem due to the extended reaction time required. However, lowering the reaction temperature to $80{ }^{\circ} \mathrm{C}$ dramatically reduced the proportion of isomerized product 28 (Entry 3 ), and switching to a less polar solvent (dioxane, ${ }^{26}$ Entry 4 ) eliminated this problem entirely but at the cost of a significantly reduced reaction rate. A solvent mixture of dioxane and NMP (1:1) resulted in shorter reaction times and greatly reduced the levels of isomerization (Entries 5 and 6). An increase in the proportion of dioxane $(2: 1)$ further reduced isomerization but also conversion (Entry 7), while a copper/ligand ratio of 1:1 maximized the reaction efficiency while maintaining minimal isomerization (Entry 8, 90\%, <1\% isomerization).

With optimized conditions in hand, attention turned to the natural products, which would require the coupling of a suitable iodinated derivative of eugenol (e.g., 4, Figure 1). This was prepared by straightforward ortho-lithiation/iodination of MOM-protected eugenol (Scheme 1). ${ }^{27}$ The application of our optimized conditions to the coupling of $\mathbf{4}$ with eugenol resulted in low yields of product 5 due to the unexpected
Table 1. Optimization of Ullmann Coupling Reaction Conditions

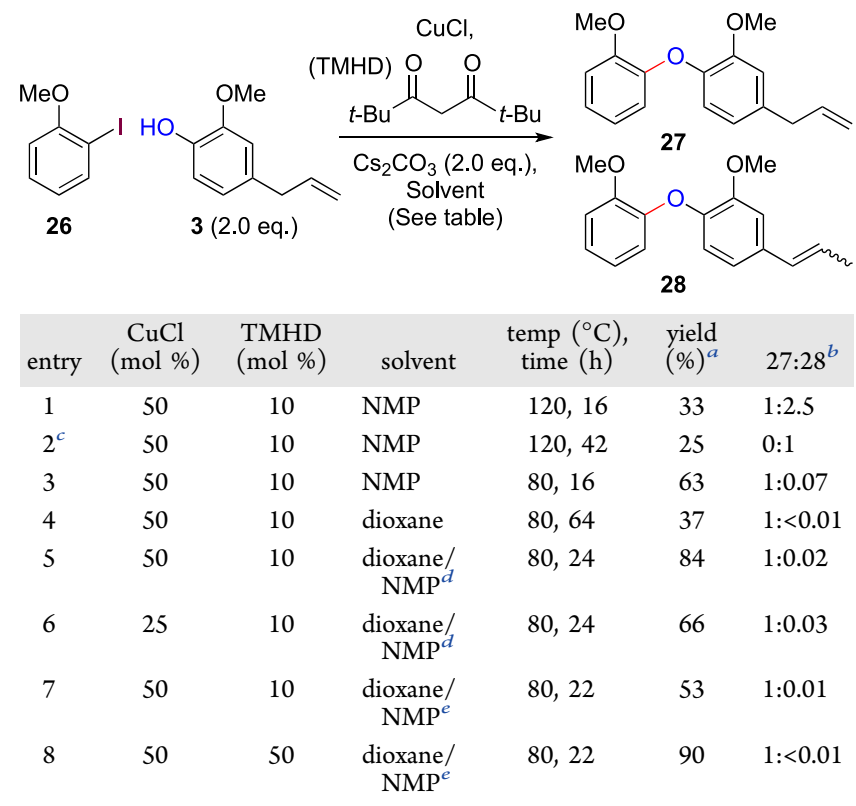

${ }^{a}$ Isolated yield. ${ }^{b}$ Determined by ${ }^{1} \mathrm{H}$ NMR spectroscopic analysis of the crude reaction mixture. ${ }^{c}$ Using 2 -bromoanisole. ${ }^{d} 1: 1$ ratio. ${ }^{e}$ 2:1 ratio.

Scheme 1. Synthesis of Natural Products 1 and 2 and Analogues 5-10
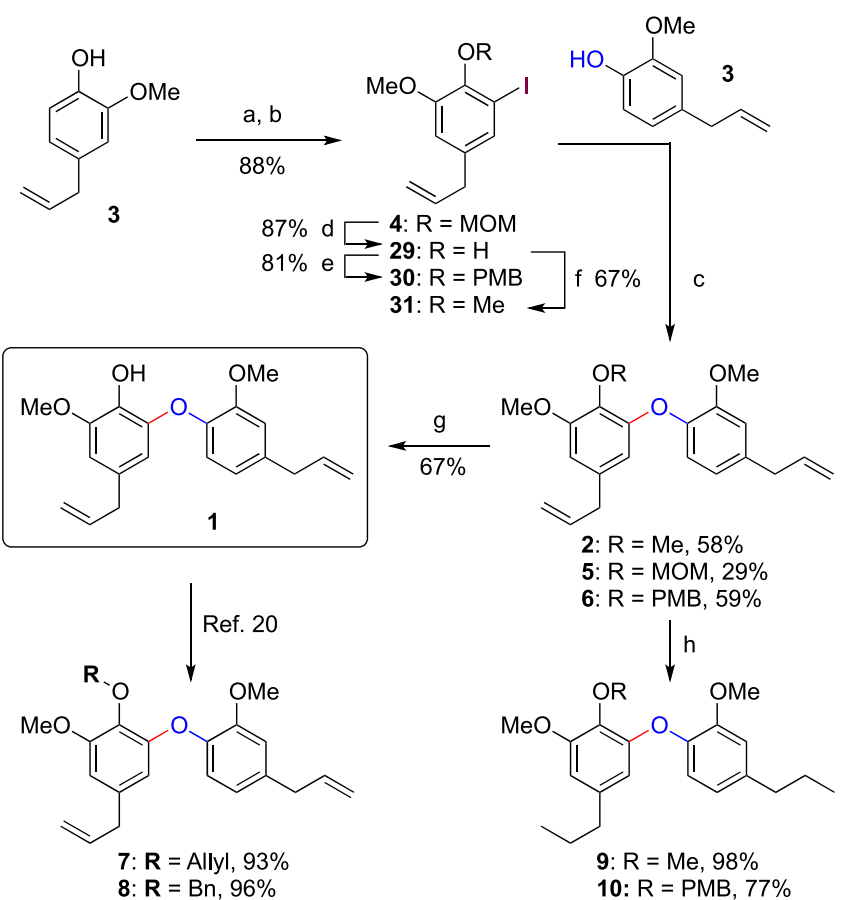

${ }^{a}$ Reagents and conditions: (a) $\mathrm{MOMCl}$ (1.5 equiv), $i-\mathrm{Pr}_{2} \mathrm{EtN}$, $\mathrm{CH}_{2} \mathrm{Cl}_{2}$; (b) $s$-BuLi (1.5 equiv), TMEDA, THF, $0{ }^{\circ} \mathrm{C}$ to rt; $\mathrm{I}_{2}$ (1.5 equiv); (c) $\mathrm{CuCl}(50 \mathrm{~mol} \%), \mathrm{TMHD}(50 \mathrm{~mol} \%), \mathrm{Cs}_{2} \mathrm{CO}_{3}$ (2 equiv), dioxane/NMP (2:1), $80{ }^{\circ} \mathrm{C}$; (d) $2 \mathrm{M} \mathrm{HCl} / \mathrm{MeOH}$ (1:10); (e) $\mathrm{PMBCl}$ (1.2 equiv), $\mathrm{K}_{2} \mathrm{CO}_{3}\left(2.5\right.$ equiv), DMF, $100{ }^{\circ} \mathrm{C}$; (f) $\mathrm{MeI}(1.4$ equiv), $\mathrm{K}_{2} \mathrm{CO}_{3}$ (4 equiv), DMF; (g) $1 \mathrm{M} \mathrm{HCl} / \mathrm{EtOH}(1: 2.5), 80{ }^{\circ} \mathrm{C}$; (h) $\mathrm{H}_{2}, \mathrm{Pd} / \mathrm{C}(30 \mathrm{~mol} \%), \mathrm{EtOH}$.

lability of the MOM protecting group under the reaction conditions. However, switching from MOM to PMB (30) or 
to $\mathrm{Me}$ (31, as required for natural product 2 ) overcame this problem, affording 6 and 2 in 59\% and 58\% yields, respectively. Interestingly, the more electron-rich "left-hand" side chain was found to be more prone to alkene isomerization during the coupling. Fortunately, the acidic conditions required for deprotection of the PMB group to deliver natural product 1 (67\%) also removed any traces of this isomerized byproduct via selective hydration of the styrenyl double bond, which is activated to protonation by the electron-rich arene. This synthetic strategy could be scaled up to enable access to $\mathbf{1}$ in gram quantities. A series of synthetic derivatives of the natural products, featuring allyl or benzyl ethers at substituent $S 1$ (7, $8)$ and/or double saturation at $S 3(9,10)$, was also prepared for reference, with 7-9 having been studied in our earlier work. $^{20}$

The modular nature of this route means it can readily be applied to the synthesis of a range of analogues not accessible from the natural products themselves in order to explore structure-activity relationships of dehydrodieugenol B. A series of 14 further compounds 11-25 was thus prepared, featuring systematic selective modification of substituents $S 1$, S2, and S3 (Scheme 2). First, a variation of the B-ring was carried out by coupling of various aryl iodides $(4,30$, and 31$)$ with "saturated" eugenol (32). This gave analogues 11-13, which allowed the investigation of the importance of B-ring side chain unsaturation on bioactivity compared to $\mathbf{1}, \mathbf{2}$, and $\mathbf{6}$. The need for either the B-ring methoxy substituent or the three-carbon side chain was probed through analogues 14/15 and $16 / 17$, respectively, which were prepared by coupling with the requisite partners 33 and 34 (we note in passing that $\mathbf{1 5}$ is itself a natural product, namely, 3-methylobovatol). ${ }^{27-29}$ Equivalent variation of A-ring functionality was achieved by coupling of eugenol with $n$-propyl iodoarene 36 , which gave analogues 18 and 19. Deletion of the A-ring three-carbon side chain and methoxy group was explored through analogues 2022 and 23/24. Interestingly, when halide 40 (lacking a methoxy group ortho to the MOM ether) was used in the Ullmann coupling, no cleavage of the MOM group was observed as had been the case with the equivalent coupling of 3 with 4 (see Scheme 1). We suggest that this can be rationalized by a steric effect where the MOM group is now able to rotate away from the Lewis-acidic copper atom during the coupling reaction, presumably a more reactive conformation for the coupling process. Finally, deletion of the C1phenol (25) was accomplished by coupling of 3,5-dibromoanisole with 3 , followed by palladium-catalyzed Kumada coupling with allylmagnesium chloride.

Our attention next turned to an evaluation of the activity of the various natural product analogues against $T$. cruzi amastigotes (evaluated microscopically using an ex vivo intracellular model with mice macrophages $)^{20}$ and trypomastigotes (resazurin in vitro assay). ${ }^{30}$ Among the compounds featuring sole modification of the $S 1$ substituent $(5-8$ and 25 , Table 2), four of the five presented improved activity against the amastigotes compared to the natural products, with $50 \%$ inhibitory concentration $\left(\mathrm{IC}_{50}\right)$ values of $4-24 \mu \mathrm{M}$, while only one demonstrated activity against the trypomastigotes $(5,6.5$ $\pm 4.9 \mu \mathrm{M})$. Analogue 6 (OPMB) showed the most promising activity $(4.0 \pm 1.4 \mu \mathrm{M})$, being approximately 20 -fold more potent than the natural product 1 against the amastigotes and with a selectivity index $>50$ and activity equivalent to benznidazole, a drug in clinical use against Chagas disease. Interestingly, in addition to the tolerance of functionalization
Scheme 2. Synthesis of Analogues 11-25
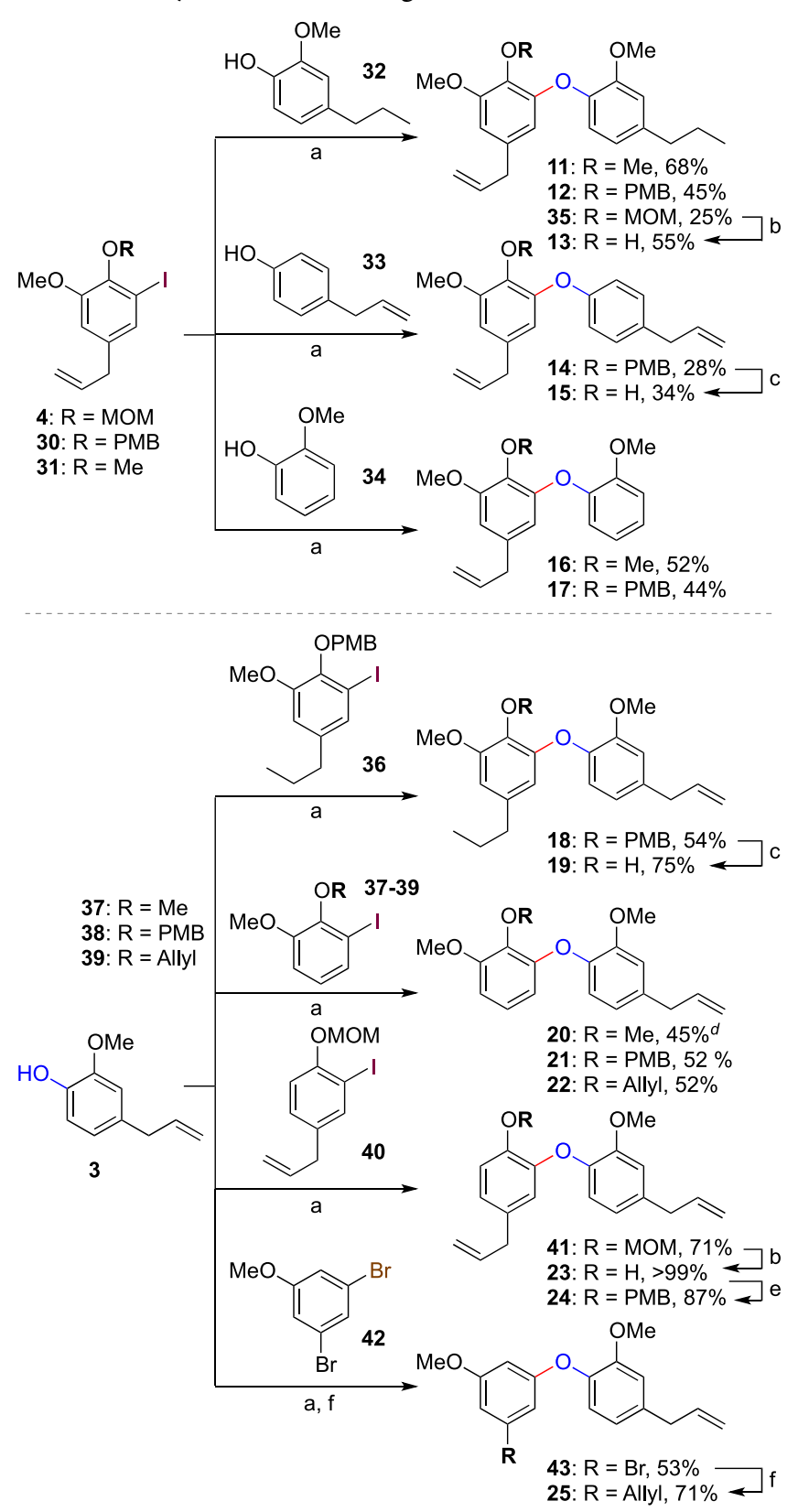

${ }^{a}$ Reagents and conditions: (a) $\mathrm{CuCl}(50 \mathrm{~mol} \%)$, TMHD (50 mol \%), $\mathrm{Cs}_{2} \mathrm{CO}_{3}$ (2 equiv), dioxane/NMP (2:1), $80{ }^{\circ} \mathrm{C}$; (b) $2 \mathrm{M} \mathrm{HCl} / \mathrm{MeOH}$ (1:10); (c) $1 \mathrm{M} \mathrm{HCl} / \mathrm{EtOH}(1: 2.5), 80^{\circ} \mathrm{C}$; (d) coupled using $\mathrm{CuI}$ $(10 \mathrm{~mol} \%), N, N$-dimethylglycine hydrochloride $(30 \mathrm{~mol} \%), \mathrm{K}_{2} \mathrm{CO}_{3}$ (2 equiv), DMSO, $80{ }^{\circ} \mathrm{C}^{26}$ (e) $\mathrm{PMBCl}$ (1.2 equiv), $\mathrm{K}_{2} \mathrm{CO}_{3}(2.5$ equiv), DMF, $100{ }^{\circ} \mathrm{C}$; (f) $\mathrm{Pd}_{2}(\mathrm{dba})_{3}(1 \mathrm{~mol} \%)$, BINAP ( $\left.1 \mathrm{~mol} \%\right)$, AllylMgCl (2.5 equiv), dioxane.

of the phenol with a variety of groups, which offers a scope for future modification, the deletion of this $S 1$ substituent also enhanced bioactivity compared to the parent natural products $(25,10.9 \mu \mathrm{M})$. It is noteworthy that all modifications of the $\mathrm{S} 1$ substituent did not lead to mammalian cytotoxicity for the highest tested concentration of $200 \mu \mathrm{M}$.

Considering modification of the S2 hydrocarbon side chains (Table 3), we first questioned whether the saturation of either or both alkenes would affect the biological activity, a potentially important consideration from a synthetic perspective where saturation would avoid the problem of alkene 
Table 2. Anti-T. cruzi Activity and Mammalian Cytotoxicity of Synthetic Analogues with a Variation of S1 Substitution ${ }^{a}$

\begin{tabular}{|c|c|c|c|c|c|c|}
\hline \multirow[b]{2}{*}{ entry } & \multirow[b]{2}{*}{ compound } & \multirow[b]{2}{*}{ S1 } & \multicolumn{2}{|c|}{$\mathrm{IC}_{50}(\mu \mathrm{M}) \pm \mathrm{SD}^{b}$} & \multirow[b]{2}{*}{$\mathrm{CC}_{50}(\mu \mathrm{M}) \pm \mathrm{SD}^{c}$} & \multirow[b]{2}{*}{$\mathrm{SI}^{d}$} \\
\hline & & & trypomastigote & amastigote & & \\
\hline 1 & $1^{e}$ & $\mathrm{OH}$ & $38.6 \pm 8.3$ & $86.5 \pm 16.2$ & $>200$ & $>2.3$ \\
\hline 2 & $2^{e}$ & $\mathrm{OMe}$ & NA & NA & $>200$ & $\mathrm{ND}$ \\
\hline 3 & 5 & OMOM & $6.5 \pm 4.9$ & $24.4 \pm 10.3$ & $>200$ & $>8.2$ \\
\hline 4 & 6 & OPMB & NA & $4.0 \pm 1.4$ & $>200$ & $>50$ \\
\hline 5 & $7^{f}$ & OAllyl & NA & $\mathrm{NA}$ & $>200$ & $\mathrm{ND}$ \\
\hline 6 & $8^{f}$ & OBn & NA & $9.5 \pm 1.3$ & $>200$ & $>21.1$ \\
\hline 7 & 25 & $\mathrm{H}$ & NA & $10.9 \pm 6.5$ & $>200$ & $>18.3$ \\
\hline 8 & benznidazole & & $17.7 \pm 1.9$ & $5.0 \pm 1.5$ & $190.6 \pm 13.4$ & 38.1 \\
\hline
\end{tabular}

${ }^{a} \mathrm{SD}$ : standard deviation; ND: not determined; NA: not active. ${ }^{b} \mathrm{IC}_{50}: 50 \%$ inhibitory concentration. ${ }^{c} \mathrm{CC}_{50}: 50 \%$ cytotoxic concentration. ${ }^{d} \mathrm{SI}$ : selectivity index, given by the ratio between $\mathrm{CC}_{50}$ in NCTC cells and $\mathrm{IC}_{50}$ in intracellular amastigotes. ${ }^{e}$ Published in ref $18 .{ }^{f}$ Published in ref 20.

Table 3. Anti-T. cruzi Activity and Mammalian Cytotoxicity of Synthetic Analogues with a Variation of S2 Substitution ${ }^{a}$

\begin{tabular}{|c|c|c|c|c|c|c|c|c|}
\hline \multirow[b]{2}{*}{ entry } & \multirow[b]{2}{*}{ compound } & \multirow[b]{2}{*}{ S1 } & \multirow[b]{2}{*}{ S2-A } & \multirow[b]{2}{*}{ S2-B } & \multicolumn{2}{|c|}{$\mathrm{IC}_{50}(\mu \mathrm{M}) \pm \mathrm{SD}^{b}$} & \multirow[b]{2}{*}{$\mathrm{CC}_{50}(\mu \mathrm{M}) \pm \mathrm{SD}^{c}$} & \multirow[b]{2}{*}{$\mathrm{SI}^{d}$} \\
\hline & & & & & trypomastigote & amastigote & & \\
\hline 1 & 13 & $\mathrm{OH}$ & Allyl & $n-\operatorname{Pr}$ & $7.6 \pm 1.9$ & $16.6 \pm 1.0$ & $42.0 \pm 3.8$ & 2.5 \\
\hline 2 & 19 & $\mathrm{OH}$ & $n-\operatorname{Pr}$ & Allyl & $4.6 \pm 3.8$ & $10.5 \pm 8.3$ & $14.2 \pm 0.1$ & 1.3 \\
\hline 3 & 11 & $\mathrm{OMe}$ & Allyl & $n-\operatorname{Pr}$ & $21.9 \pm 6.1$ & $11.7 \pm 7.0$ & $>200$ & $>17.1$ \\
\hline 4 & $9^{e}$ & $\mathrm{OMe}$ & $n-\operatorname{Pr}$ & $n-\operatorname{Pr}$ & NA & $13.3 \pm 1.2$ & $>200$ & $>15.0$ \\
\hline 5 & 10 & OPMB & $n-\operatorname{Pr}$ & $n-\operatorname{Pr}$ & NA & $5.5 \pm 3.5$ & $>200$ & $>36.4$ \\
\hline 6 & 12 & OPMB & Allyl & $n$-Pr & NA & $8.6 \pm 2.1$ & $>200$ & $>23.3$ \\
\hline 7 & 18 & OPMB & $n-\operatorname{Pr}$ & Allyl & NA & $13.4 \pm 5.4$ & $>200$ & $>14.9$ \\
\hline 8 & 16 & $\mathrm{OMe}$ & Allyl & $\mathrm{H}$ & $20.3 \pm 0.4$ & NA & $>200$ & ND \\
\hline 9 & 20 & $\mathrm{OMe}$ & $\mathrm{H}$ & Allyl & $63.1 \pm 6.2$ & $25.7 \pm 12.2$ & $>200$ & $>7.8$ \\
\hline 10 & 17 & OPMB & Allyl & $\mathrm{H}$ & NA & NA & $>200$ & ND \\
\hline 11 & 21 & OPMB & $\mathrm{H}^{\prime}$ & Allyl & NA & NA & $>200$ & ND \\
\hline 12 & 22 & OAllyl & $\mathrm{H}$ & Allyl & NA & NA & $>200$ & ND \\
\hline 13 & benznidazole & & & & $17.7 \pm 1.9$ & $5.0 \pm 1.5$ & $190.6 \pm 13.4$ & 38.1 \\
\hline
\end{tabular}

${ }^{a}$ SD: standard deviation; ND: not determined; NA: not active. ${ }^{b} \mathrm{IC}_{50}: 50 \%$ inhibitory concentration. ${ }^{c} \mathrm{CC}_{50}: 50 \%$ cytotoxic concentration. ${ }^{d}$ SI: selectivity index, given by the ratio between $\mathrm{CC}_{50}$ in NCTC cells and $\mathrm{IC}_{50}$ in intracellular amastigotes. ${ }^{e}$ Published in ref 20.

Table 4. Anti-T. cruzi Activity and Mammalian Cytotoxicity of Synthetic Analogues with S3 Deletions ${ }^{a}$

\begin{tabular}{|c|c|c|c|c|c|c|c|c|}
\hline \multirow[b]{2}{*}{ entry } & \multirow[b]{2}{*}{ compound } & \multirow[b]{2}{*}{ S1 } & \multirow[b]{2}{*}{ S3-A } & \multirow[b]{2}{*}{ S3-B } & \multicolumn{2}{|c|}{$\mathrm{IC}_{50}(\mu \mathrm{M}) \pm \mathrm{SD}^{b}$} & \multirow[b]{2}{*}{$\mathrm{CC}_{50}(\mu \mathrm{M}) \pm \mathrm{SD}^{c}$} & \multirow[b]{2}{*}{$\mathrm{SI}^{d}$} \\
\hline & & & & & trypomastigote & amastigote & & \\
\hline 1 & 23 & $\mathrm{OH}$ & $\mathrm{H}$ & $\mathrm{OMe}$ & $2.5 \pm 1.3$ & $7.7 \pm 1.3$ & $128.6 \pm 5.2$ & 16.7 \\
\hline 2 & 24 & OPMB & $\mathrm{H}$ & $\mathrm{OMe}$ & NA & $11.6 \pm 8.4$ & $>200$ & $>17.2$ \\
\hline 3 & 15 & $\mathrm{OH}$ & $\mathrm{OMe}$ & $\mathrm{H}$ & $4.6 \pm 3.0$ & $22.5 \pm 18.8$ & $123.4 \pm 9.4$ & 5.5 \\
\hline 4 & 14 & OPMB & $\mathrm{OMe}$ & $\mathrm{H}$ & NA & $11.0 \pm 2.3$ & $>200$ & $>18.2$ \\
\hline 5 & benznidazole & & & & $17.7 \pm 1.9$ & $5.0 \pm 1.5$ & $190.6 \pm 13.4$ & 38.1 \\
\hline
\end{tabular}

${ }^{a} \mathrm{SD}$ : standard deviation; ND: not determined; NA: not active. ${ }^{b} \mathrm{IC}_{50}: 50 \%$ inhibitory concentration. ${ }^{c} \mathrm{CC}$ : $: 50 \%$ cytotoxic concentration. ${ }^{d} \mathrm{SI}$ : selectivity index, given by the ratio between $\mathrm{CC}_{50}$ in NCTC cells and $\mathrm{IC}_{50}$ in intracellular amastigotes.

isomerization during Ullmann coupling. Pleasingly, a consistent and potent activity was observed against $T$. cruzi amastigotes irrespective of which side chain was hydrogenated (or indeed both, 5.5-16.6 $\mu \mathrm{M}$, Entries 1-7). For the phenols 13 and 19, significant mammalian toxicity was observed, although alkylation of the phenol as methyl or PMB ether avoided this problem. In contrast, analogue 11 was the only derivative of this subset aside from 13 and 19 to display activity against the trypomastigote form. We next examined whether deletion of the S2 side chains was tolerated. For activity against amastigotes, this revealed that both side chains are likely required (Entries 8-12), with only analogue $\mathbf{1 8}$ displaying appreciable bioactivity (albeit reduced compared to derivatives featuring two side chains, Entries 1-7). It is curious that this deletion led to activity for compound 16, a direct analogue of 2, which in its native form is apparently inactive (Table 1, Entry 2). Finally, the effect of S3 deletion was studied through analogues 23/24 (A-ring) and 14/15 (Bring). In all cases (Table 4), appreciable activity was observed against the amastigote form of the parasite and also against 
trypomastigotes for the free phenols, albeit again at a cost of mammalian toxicity. Given the improved efficiency of Ullmann coupling of iodide 41 (Scheme 2), which lacks the A-ring methoxy substituent, this deletion may again offer a synthetic benefit for access to further natural product analogues.

The Drugs for Neglected Disease Initiative (DNDi) defines the "hit criteria" for Chagas disease as a compound accessed by a synthetic pathway of up to 8 steps, with an $\mathrm{IC}_{50}$ value against amastigotes lower that $10 \mu \mathrm{M}$ and a selectivity index of at least $10 .^{31}$ Among the 21 analogues studied in this work, five meet these criteria, displaying a potency equivalent to the current therapeutic agent benznidazole, and a further seven display activity of $<15 \mu \mathrm{M}$. Only those analogues possessing a free phenol exhibited mammalian toxicity. In general, low activity was observed against the extracellular trypomastigotes compared to the intracellular amastigotes, which may suggest that the compounds' mode of action is implicated in amastigote replication or a possible immunomodulatory effect whereby the compounds activate the macrophage, rather than acting on the parasite directly.

The following trends against the amastigote form of T. cruzi emerge from the SAR study (Figure 2): (1) The presence of

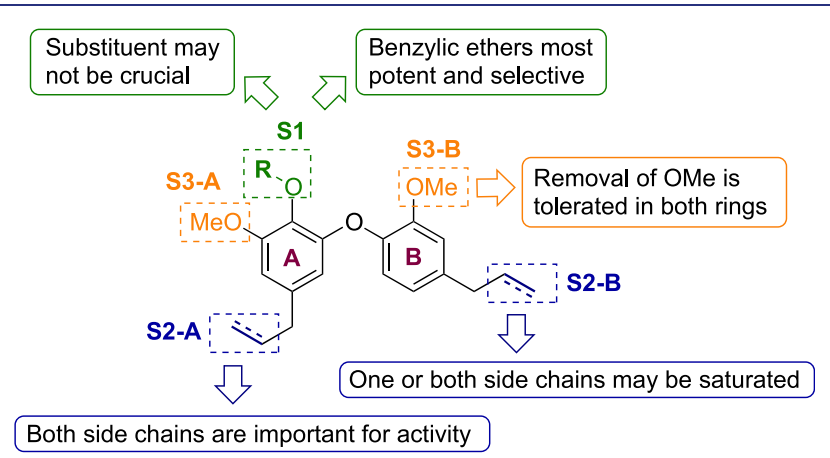

Figure 2. SAR trends for the dehydrodieugenol scaffold.

both $\mathrm{S} 2$ side chains is likely important for activity, although one or both may be saturated. (2) Either of the S3 methoxy groups may be removed without a significant effect on antiparasitic activity, which may be of utility from a synthetic perspective. (3) The S1 substituent may not be crucial (Table 3) but can also accommodate functionalization with various ether groups, which in general reduce toxicity compared to the equivalent phenols (e.g., 13 vs 11 or 12,19 vs 18,23 vs 24 ). In particular, the most potent analogues $(6,8,10$, and 12$)$ feature benzylic ethers at this position, suggesting there is significant scope for further exploration of this substituent vector. In all, this study shows that the dehydrodieugenol framework offers a robust platform for further analogue design, including the synthesis of candidates featuring improved "drug-like" properties.

In conclusion, a robust synthetic route to the dehydrodieugenol natural products has been developed, which centers on an Ullmann coupling to form the biaryl ether linkage. This approach enabled the preparation of 21 synthetic analogues, most of which are not accessible from the natural products themselves. While further mechanism of action and pharmacokinetic studies as well as additional analogues that encompass more significant variations on the aromatic rings and their side chains will be needed to inform the design process, the study shows that this biaryl ether scaffold has much flexibility and promise for the discovery of bioactive natural-product based antiparasitic agents.

\section{METHODS}

Ethics Statement. BALB/c mice were obtained from the animal breeding facility at the Instituto Adolfo Lutz, Brazil. The animals were maintained in sterilized cages under a controlled environment and received water and food ad libitum. All procedures performed were previously approved by the Animal Care and Use Committee from Instituto Adolfo Lutz, Secretary of Health of Sao Paulo State (Project number CEUA 05/2018) in agreement with the Guide for the Care and Use of Laboratory Animals from the National Academy of Sciences.

Parasites and Mammalian Cell Maintenance. Macrophages were collected from the peritoneal cavity of BALB/c mice by washing them with RPMI-1640 medium supplemented with $10 \%$ fetal calf serum and were maintained at 37 ${ }^{\circ} \mathrm{C}$ in a $5 \% \mathrm{CO}_{2}$ humidified incubator. Trypomastigotes of T. cruzi (Y strain) were maintained in Rhesus monkey kidney cells (LLC-MK2, ATCC CCL 7) and cultivated in RPMI-1640 medium supplemented with $2 \%$ fetal calf serum at $37{ }^{\circ} \mathrm{C}$ in a $5 \% \mathrm{CO}_{2}$ humidified incubator. Murine conjunctive cells (NCTC clone 929, ATCC) were maintained in RPMI-1640 supplemented with $10 \% \mathrm{FBS}$ at $37^{\circ} \mathrm{C}$ in a $5 \% \mathrm{CO}_{2}$ humidified incubator. $^{20}$

Antitrypomastigote Assay. LLC-MK2-derived trypomastigotes were seeded $\left(1 \times 10^{6}\right.$ cells/well $)$ in 96-well plates and incubated with the compounds serially diluted 2-fold (up to $100 \mu \mathrm{M}$ ) for $24 \mathrm{~h}$ in RPMI 1640 medium at $37{ }^{\circ} \mathrm{C}$ in a $5 \%$ $\mathrm{CO}_{2}$ humidified incubator. Subsequently, resazurin $(0.011 \%$ in PBS) was added for $24 \mathrm{~h}$ to check the parasite viability. ${ }^{30}$ The optical density was determined in the FilterMax F5 (Molecular Devices) at $570 \mathrm{~nm}$. Benznidazole was used as the standard.

Antiamastigote Assay. Peritoneal macrophages $\left(1 \times 10^{5}\right.$ cells/well), collected from the peritoneal cavity of the BALB/c mice, were seeded in 16-well chamber slides (NUNC, Thermo Fisher Scientific) and infected with trypomastigotes (10:1, parasite/macrophage ratio). After $2 \mathrm{~h}$, the compounds (in concentrations of 30-0.23 $\mu \mathrm{M}$ ) were incubated with infected macrophages for $48 \mathrm{~h}$ at $37{ }^{\circ} \mathrm{C}$ in a $5 \% \mathrm{CO}_{2}$ humidified incubator. The slides were fixed with $\mathrm{MeOH}$, stained with Giemsa, and observed under a light microscope (EVOS M5000, Termo, USA) with digital image equipment. The 50\% inhibitory concentration $\left(\mathrm{IC}_{50}\right)$ values were determined by the infection index. ${ }^{20}>90 \%$ infection of macrophages was established in this assay.

Cytotoxicity against Mammalian Cells. Fibroblast NCTC cells (clone 929) $\left(6 \times 10^{4}\right.$ cells/well) were seeded in 96-well plates and incubated with the compounds (200-1.56 $\mu \mathrm{M})$ for $48 \mathrm{~h}$ at $37{ }^{\circ} \mathrm{C}$ in a $5 \% \mathrm{CO}_{2}$ humidified incubator. The $50 \%$ cytotoxic concentration $\left(\mathrm{CC}_{50}\right)$ was determined by the MTT colorimetric assay. ${ }^{32}$ The selectivity index (SI) was determined as $\mathrm{CC}_{50} / \mathrm{IC}_{50}$ against amastigotes.

Statistical Analysis. $\mathrm{IC}_{50}$ and $\mathrm{CC}_{50}$ values were calculated using a sigmoid dose-response curve in GraphPad Prism 6.0 software (GraphPad Software, San Diego, CA, USA). The assays were repeated at least twice, and the samples were tested in duplicate. 


\section{ASSOCIATED CONTENT}

\section{(3) Supporting Information}

The Supporting Information is available free of charge at https://pubs.acs.org/doi/10.1021/acsinfecdis.0c00523.

Synthetic procedures and copies of ${ }^{1} \mathrm{H}$ and ${ }^{13} \mathrm{C}$ NMR data for all novel compounds (PDF)

\section{AUTHOR INFORMATION}

\section{Corresponding Authors}

Andre G. Tempone - Centre for Parasitology and Mycology, Instituto Adolfo Lutz, São Paulo 01246-000, Brazil; ๑ orcid.org/0000-0003-2559-7344; Email: atempone@ ial.sp.gov.br

Edward A. Anderson - Chemistry Research Laboratory, Oxford OX1 3TA, United Kingdom; (1) orcid.org/0000-0002-41490494; Email: edward.anderson@chem.ox.ac.uk

\section{Authors}

Claire E. Sear - Chemistry Research Laboratory, Oxford OX1 3TA, United Kingdom

Pauline Pieper - Chemistry Research Laboratory, Oxford OX1 3TA, United Kingdom

Maiara Amaral - Faculdade de Medicina, Universidade de São Paulo, São Paulo 05403-000, Brazil; Centre for Parasitology and Mycology, Instituto Adolfo Lutz, São Paulo 01246-000, Brazil

Maiara M. Romanelli - Centre for Parasitology and Mycology, Instituto Adolfo Lutz, São Paulo 01246-000, Brazil

Thais A. Costa-Silva - Centre for Parasitology and Mycology, Instituto Adolfo Lutz, São Paulo 01246-000, Brazil

Marius M. Haugland - Chemistry Research Laboratory, Oxford OX1 3TA, United Kingdom

Joseph A. Tate - Syngenta Ltd., Jealott's Hill International Research Centre, Bracknell RG42 6EY, United Kingdom

João H. G. Lago - Centre of Natural Sciences and Humanities, Federal University of $A B C$ (UFBC), Santo Andre, São Paulo 09210-580, Brazil

Complete contact information is available at:

https://pubs.acs.org/10.1021/acsinfecdis.0c00523

\section{Author Contributions}

The manuscript was written through contributions of all authors.

Notes

The authors declare no competing financial interest.

\section{ACKNOWLEDGMENTS}

The authors wish to thank Hannah Asiki for assistance with the synthesis of compounds 32 and 35. C.E.S. thanks the EPSRC Centre for Doctoral Training in Synthesis for Biology and Medicine for a studentship (EP/L015838/1), generously supported by AstraZeneca, Diamond Light Source, Defence Science and Technology Laboratory, Evotec, GlaxoSmithKline, Janssen, Novartis, Pfizer, Syngenta, Takeda, UCB, and Vertex. P.P. thanks the Swiss National Science Foundation for an SNSF Fellowship and the Marie Skłodowska-Curie actions for an Individual Fellowship (GA No. 832700). E.A.A. thanks the Oxford Internal GCRF Research England Fund (Grant No. 0006019) and the EPSRC for additional support (EP/ S013172/1). This work was funded by grants and fellowships provided from São Paulo State Research Foundation (FAPESP
2018/10279-6, 2018/25128-3), Coordenação de Aperfeiçoamento de Pessoal de Nivel Superior (CAPES).

\section{ABBREVIATIONS}

BINAP, (2,2'-bis(diphenylphosphino)-1,1'-binaphthyl); CCL2, CC chemokine ligand 2; CCR2, CC chemokine receptor 2; CCR5, CC chemokine receptor 5; DMF, $N, N$ dimethylformamide; MOM, methoxymethyl; NMP, N-methylpyrrolidinone; TMEDA, $N, N, N^{\prime}, N^{\prime}$-tetramethylethylenediamine; PMB, para-methoxybenzyl; TLC, thin layer chromatography; TMHD, 2,2,6,6-tetramethyl-3,5-heptanedione

\section{REFERENCES}

(1) Hollingsworth, T. D., Adams, E. R., Anderson, R. M., Atkins, K., Bartsch, S., Basáñez, M.-G., Behrend, M., Blok, D. J., Chapman, L. A. C., Coffeng, L., Courtenay, O., Crump, R. E., de Vlas, S. J., Dobson, A., Dyson, L., Farkas, H., Galvani, A. P., Gambhir, M., Gurarie, D., Irvine, M. A., Jervis, S., Keeling, M. J., Kelly-Hope, L., King, C., Lee, B. Y., Le Rutte, E. A., Lietman, T. M., Ndeffo-Mbah, M., Medley, G. F., Michael, E., Pandey, A., Peterson, J. K., Pinsent, A., Porco, T. C., Richardus, J. H., Reimer, L., Rock, K. S., Singh, B. K., Stolk, W., Swaminathan, S., Torr, S. J., Townsend, J., Truscott, J., Walker, M., Zoueva, A., and NTD Modelling Consortium (2015) Quantitative analyses and modelling to support achievement of the 2020 goals for nine neglected tropical diseases. Parasites Vectors 8, 630.

(2) De Rycker, M., Baragaña, B., Duce, S. L., and Gilbert, I. H. (2018) Challenges and recent progress in drug discovery for tropical diseases. Nature 559, 498-506.

(3) (Accessed 2020-07-21) Chagas disease (also known as American trypanosomiasis), https://www.who.int/news-room/fact-sheets/ detail/chagas-disease-(american-trypanosomiasis).

(4) Sanchez-Valdez, F. J., Padilla, A., Wang, W., Orr, D., and Tarleton, R. L. (2018) Spontaneous dormancy protects Trypanosoma cruzi during extended drug exposure. eLife 7, No. e34039.

(5) Silva-Dos-Santos, D., Barreto-De-Albuquerque, J., Guerra, B., Moreira, O. C., Berbert, L. R., Ramos, M. T., Mascarenhas, B. A. S., Britto, C., Morrot, A., Serra Villa-Verde, D. M., Garzoni, L. R., Savino, W., Cotta-De-Almeida, V., and Meis, J. d. (2017) Unraveling Chagas disease transmission through the oral route: Gateways to Trypanosoma cruzi infection and target tissues. PLoS Neglected Trop. Dis. 11, No. e0005507.

(6) Ribeiro, V., Dias, N., Paiva, T., Hagström-Bex, L., Nitz, N., Pratesi, R., and Hecht, M. (2020) Current trends in the pharmacological management of Chagas disease. Int. J. Parasitol.: Drugs Drug Resist. 12, 7-17.

(7) Field, M. C., Horn, D., Fairlamb, A. H., Ferguson, M. A. J., Gray, D. W., Read, K. D., De Rycker, M., Torrie, L. S., Wyatt, P. G., Wyllie, S., and Gilbert, I. H. (2017) Anti-trypanosomatid drug discovery: an ongoing challenge and a continuing need. Nat. Rev. Microbiol. 15, 217-231.

(8) Wang, S., Dong, G., and Sheng, C. (2019) Structural Simplification of Natural Products. Chem. Rev. 119, 4180-4220.

(9) Villalta, F., and Rachakonda, G. (2019) Advances in preclinical approaches to Chagas disease drug discovery. Expert Opin. Drug Discovery 14, 1161-1174.

(10) Bhattacharya, A., Corbeil, A., do Monte-Neto, R. L., and Fernandez-Prada, C. (2020) Of Drugs and Trypanosomatids: New Tools and Knowledge to Reduce Bottlenecks in Drug Discovery. Genes 11, 722.

(11) Newman, D. J., and Cragg, G. M. (2016) Natural Products as Sources of New Drugs from 1981 to 2014. J. Nat. Prod. 79, 629-661.

(12) da Rosa, R., Schenkel, E. P., and Campos Bernardes, L. S. (2020) Semisynthetic and newly designed derivatives based on natural chemical scaffolds: moving beyond natural products to fight Trypanosoma cruzi. Phytochem. Rev. 19, 105-122.

(13) Santos, S. S., de Araújo, R. V., Giarolla, J., Seoud, O. E., and Ferreira, E. I. (2020) Searching for drugs for Chagas disease, 
leishmaniasis and schistosomiasis: a review. Int. J. Antimicrob. Agents $55,105906$.

(14) Zimmermann, L. A., de Moraes, M. H., da Rosa, R., de Melo, E. B., Paula, F. R., Schenkel, E. P., Steindel, M., and Bernardes, L. S. C. (2018) Synthesis and SAR of new isoxazole-triazole bis-heterocyclic compounds as analogues of natural lignans with antiparasitic activity. Bioorg. Med. Chem. 26, 4850-4862.

(15) Fraser, A. L., Menzies, S. K., King, E. F. B., Tulloch, L. B., Gould, E. R., Zacharova, M. K., Smith, T. K., and Florence, G. J. (2018) Design and Synthesis of Broad Spectrum Trypanosomatid Selective Inhibitors. ACS Infect. Dis. 4, 560-567.

(16) Cheuka, P. M., Mayoka, G., Mutai, P., and Chibale, K. (2017) The Role of Natural Products in Drug Discovery and Development against Neglected Tropical Diseases. Molecules 22, 58.

(17) Wells, T. N. C. (2011) Natural products as starting points for future anti-malarial therapies: going back to our roots? Malar. J. 10, S3.

(18) Grecco, S. S., Costa-Silva, T. A., Jerz, G., de Sousa, F. S., Londero, V. S., Galuppo, M. K., Lima, M. L., Neves, B. J., Andrade, C. H., Tempone, A. G., and Lago, J. H. G. (2017) Neolignans from leaves of Nectandra leucantha (Lauraceae) display in vitro antitrypanosomal activity via plasma membrane and mitochondrial damages. Chem.-Biol. Interact. 277, 55-61.

(19) Costa-Silva, T. A. d., Grecco, S. S., de Sousa, F. S., Lago, J. H. G., Martins, E. G. A., Terrazas, C. A., Varikuti, S., Owens, K. L., Beverley, S. M., Satoskar, A. R., and Tempone, A. G. (2015) Immunomodulatory and Antileishmanial Activity of Phenylpropanoid Dimers Isolated from Nectandra leucantha. J. Nat. Prod. 78, 653-657. (20) Ferreira, D. D., Sousa, F. S., Costa-Silva, T. A., Reimão, J. Q., Torrecilhas, A. C., Johns, D. M., Sear, C. E., Honorio, K. M., Lago, J. H. G., Anderson, E. A., and Tempone, A. G. (2019) Dehydrodieugenol B derivatives as antiparasitic agents: Synthesis and biological activity against Trypanosoma cruzi. Eur. J. Med. Chem. 176, 162-174. (21) Giri, R., Brusoe, A., Troshin, K., Wang, J. Y., Font, M., and Hartwig, J. F. (2018) Mechanism of the Ullmann Biaryl Ether Synthesis Catalyzed by Complexes of Anionic Ligands: Evidence for the Reaction of Iodoarenes with Ligated Anionic CuI Intermediates. J. Am. Chem. Soc. 140, 793-806.

(22) Evano, G., Wang, J., and Nitelet, A. (2017) Metal-mediated C$\mathrm{O}$ bond forming reactions in natural product synthesis. Org. Chem. Front. 4, 2480-2499.

(23) Sambiagio, C., Marsden, S. P., Blacker, A. J., and McGowan, P. C. (2014) Copper catalysed Ullmann type chemistry: from mechanistic aspects to modern development. Chem. Soc. Rev. 43, $3525-3550$.

(24) Kwak, J.-H., In, J.-K., Lee, M.-S., Choi, E.-H., Lee, H., Hong, J. T., Yun, Y.-P., Lee, S. J., Seo, S.-Y., Suh, Y.-G., and Jung, J.-K. (2008) Concise synthesis of Obovatol: Chemoselective ortho-bromination of phenol and survey of $\mathrm{Cu}$-catalyzed diaryl ether couplings. Arch. Pharmacal Res. 31, 1559-1563.

(25) Buck, E., Song, Z. J., Tschaen, D., Dormer, P. G., Volante, R. P., and Reider, P. J. (2002) Ullmann Diaryl Ether Synthesis: Rate Acceleration by 2,2,6,6-Tetramethylheptane-3,5-dione. Org. Lett. 4, $1623-1626$.

(26) Ma, D., and Cai, Q. (2003) N, N-Dimethyl Glycine-Promoted Ullmann Coupling Reaction of Phenols and Aryl Halides. Org. Lett. 5, 3799-3802.

(27) Garnier, T., Danel, M., Magné, V., Pujol, A., Bénéteau, V., Pale, P., and Chassaing, S. (2018) Copper(I)-USY as a Ligand-Free and Recyclable Catalyst for Ullmann-Type O-, N-, S-, and C-Arylation Reactions: Scope and Application to Total Synthesis. J. Org. Chem. 83, 6408-6422.

(28) Kijjoa, A., Pinto, M. M. M., Tantisewie, B., and Herz, W. (1989) A biphenyl type neolignan and a biphenyl ether from Magnolia henryi. Phytochemistry 28, 1284-1286.

(29) Pilkington, L. I., and Barker, D. (2015) Synthesis of 3Methylobovatol. Synlett 26, 2425-2428.

(30) Martins, L. F., Mesquita, J. T., Pinto, E. G., Costa-Silva, T. A., Borborema, S. E. T., Galisteo Junior, A. J., Neves, B. J., Andrade, C.
H., Shuhaib, Z. A., Bennett, E. L., Black, G. P., Harper, P. M., Evans, D. M., Fituri, H. S., Leyland, J. P., Martin, C., Roberts, T. D., Thornhill, A. J., Vale, S. A., Howard-Jones, A., Thomas, D. A., Williams, H. L., Overman, L. E., Berlinck, R. G. S., Murphy, P. J., and Tempone, A. G. (2016) Analogues of Marine Guanidine Alkaloids Are in Vitro Effective against Trypanosoma cruzi and Selectively Eliminate Leishmania (L.) infantum Intracellular Amastigotes. J. Nat. Prod. 79, 2202-2210.

(31) Katsuno, K., Burrows, J. N., Duncan, K., van Huijsduijnen, R. H., Kaneko, T., Kita, K., Mowbray, C. E., Schmatz, D., Warner, P., and Slingsby, B. T. (2015) Hit and lead criteria in drug discovery for infectious diseases of the developing world. Nat. Rev. Drug Discovery $14,751-758$.

(32) Tada, H., Shiho, O., Kuroshima, K.-i., Koyama, M., and Tsukamoto, K. (1986) An improved colorimetric assay for interleukin 2. J. Immunol. Methods 93, 157-165. 